\title{
NGHIÊN CỨU TÍNH TOÁN BỀN KẾT CẤU KHUNG XƯƠNG SÁT-XI LIỀN KHỐI CHỊU LỰC CHO Ô TÔ KHÁCH 29/34 CHỖ SAMCO ISUZU
}

\author{
NGUYẼ̃N THÀNH TÂM, NGUYẼ̃N VĂN SỸ \\ Khoa Công nghệ Động lực, Trương Đại học Công nghiệp Thành phố Hồ Chi Minh \\ nguyenthanhtam@iuh.edu.vn
}

Tóm tắt. Đối với sát-xi ô tô khách, cấu trúc khung chịu lực liền khối có thể mang lại tính gọn nhẹ hơn khung xương và sát-xi rời. Tuy nhiên tính phức tạp của các thanh thép được gia cố có thể ảnh hưởng đến độ cứng vững của kết cấu khi thiết kế bền. Nghiên cứu này thực hiện phân tích mô phỏng bền kết cấu khung xương sát-xi liền khối chịu lực monocoque ô tô khách dưới tải trọng tĩnh. Đầu tiên, mô hình $3 \mathrm{D}$ và phần tử hữu hạn của khung xương sát-xi được xây dựng bởi phần mềm CATIA và ALTAIR OPTISTRUCT. Thứ hai, phân tích trạng thái bền tĩnh kết cấu khung xương sát-xi cho bốn quá trình làm việc của xe trên đường như xe chuyển động thẳng đều (điều kiện uốn), xe chạy trên đường gồ ghề (điều kiện xoắn), xe phanh gấp (điều kiện phanh), xe chạy vào đường cong (điều kiện quay vòng). Kết quả tính toán mô phỏng thực tế cho thấy quá trình xoắn có giá trị ứng suất, chuyển vị lớn nhất và nằm trong giá trị cho phép. Kết cấu khung xương sát-xi xe thỏa mãn được độ bền và độ cứng kết cấu.

Từ khóa: Kết cấu xe khách, phần tử hữu hạn, mô phỏng, phân tích bền tĩnh

\section{STRENGTH RESEARCH OF MONOCOQUE BUS BODY FRAME STRUCTURE}

\begin{abstract}
For chassis structure in bus body, the monocoque frame might bring lighter than the single frame. However, the complicated structure of the monocoque frame leads to the requirement of trade-off for strength in crashworthiness design. This paper presents an analysis of simulation of monocoque frame under static loading. First, the 3D and finite element of monocoque bus frame structure are builted by the CATIA and ALTAIR OPTISTRUCT software. Second, the static analysis of bus frame structures is carried out with different boundary and loading conditions as bending, torsing, braking, cornering. The simulation results show the fact that, the highest values of stress and deformation displacement of bus frame with the torsing condition. The bus frame safety requirements of strength and stiffness are also well met.
\end{abstract}

Key words: bus structure, finite element, simulation, static analysis

\section{LờI NÓI ĐẦU}

Kết cấu khung xương và sát-xi rời của xe khách hiện nay đang được dùng phổ biến tại Việt Nam như các dòng xe 29/34 chỗ Samco Isuzu, xe buýt B47 do Công ty Samco đóng mới trên nền sát-xi hãng Isuzu cung cấp, nhược điểm của kết cấu dạng này là hấp thụ xung lực kém, có khối lượng nặng, dẫn đến hiệu suất mang lại thấp và khả năng tiết kiệm nhiên liệu cũng vì thế mà giảm đi rất nhiều. Công nghệ khung xương sát-xi liền khối chịu lực monocoque được chể tạo từ những thanh thép chịu lực tốt, được thiết kế và lắp ráp thành từng mảng, mảng sàn, mảng hông trái phải, mảng đuôi, mảng đầu, mảng sát-xi và lắp ghép lại thành khung xe. Các thanh thép được gia cố chéo nhằm tạo độ cứng vững và an toàn khi chịu lực. Bên cạnh đó, thân xe liền khối monocoque còn giảm được khối lượng toàn thân xe chịu tải nên không sử dụng sát-xi rời. Do đó, kết cấu khung xương sát-xi liền khối chịu lực monocoque có trọng lượng được giảm đáng kể và tạo độ an toàn cho hành khách.

Nghiên cứu thiết kế chế tạo hệ khung xương sát-xi liền khối chịu lực monocoque hiện nay đã được thực hiện và ứng dụng ở các nước có nền công nghiệp ô tô phát triển[1-2], các công ty ô tổ trong nước hiện có thực hiện lắp ráp, sản xuất xe có hệ khung xương sát-xi liền khối chịu lực monocoque, tuy nhiên chưa có công trình nghiên cứu hệ khung xương xe 29/34 chỗ được công bố. Do đó, thiết kế chế tạo hệ khung xương sát-xi liền khối chịu lực monocoque cho ô tô khách 29/34 chỗ ứng dụng trong nước là việc làm cần thiết nhằm làm chủ công nghệ, tăng tî̉ lệ nội địa hóa sản phẩm trong nước, vì hiện nay hệ khung xương sát-xi xe 29/34 chỗ chủ yếu nhập ngoại về cải tiến, lắp ráp. 
Nhiều tác giả sử dụng phương pháp phần tử hữu hạn phân tích các trạng thái tĩnh kết cấu thân xe khách [17]; tác giả Liu Jiang tối ưu hóa kết cấu ô tô khách trên cơ sở phân tích hình thái dao động kết cấu [8]. Tác giả Trần Hữu Nhân tiến hành nghiên cứu tính toán tối ưu hóa kết cấu thân xe buýt, tuy nhiên tác giả không nêu ra độ tin cậy hàm mục tiêu và hàm điều kiện, do đó chưa thể hiện được độ tin cậy trong quá trình tối ưu hóa [9]; tác giả Nguyễn Thành Tâm tối ưu hóa kết cấu khung xương và sát-xi ô tô khách, tuy nhiên việc nghiên cứu kết cấu khung xương sát-xi liền khối monocoque cho xe 29/34 chỗ chưa thực hiện [10]; Tác giả Nguyễn Quang Anh nghiên cứu tính toán động lực học của ô tô và độ bền của khung xương khi ô tô xảy ra va chạm trực diện, chưa thực hiện nghiên cứu bền tĩnh kết cấu khung xương sát-xi liền khối chịu lực [11].

Nghiên cứu này xây dựng mô hình $3 \mathrm{D}$ xe, ứng dụng phần mềm ALTAIL HYPERWORKS trong môi trường OPTISTRUCT tiến hành xây dựng mô hình phần tử hữu hạn, mô phỏng, phân tích trạng thái bền tĩnh kết cấu khung xương sát-xi cho bốn quá trình làm việc của xe trên đường như quá trình uốn, quá trình xoắn, quá trình phanh, quá trình quay vòng.

\section{XÂY DỰ̂ MÔ HÌNH TÍNH TOÁN PHÂN TÍCH}

\subsection{Mô hình kết cấu khung xương sát-xi}

Mô hình 3D tổng thể xe khách 29/34 chỗ ngồi với chiều dài tổng thể xe $\mathrm{L}=8,7 \mathrm{~m}$, chiều rộng tổng thể $\mathrm{B}=$ 2,4 m với 29/34 chỗ được phối hợp với nhà sản xuất xây dựng, thể hiện ở hình 1 .

Khung xương sát-xi xe khách gồm 6 bộ phận chính: Mảng đầu, mảng đuôi, mảng mui, mảng hông trái phải, mảng sàn và sát-xi. Khung xương xe được thiết kế các bộ phận với nhiều loại thép có tiết diện khác nhau đảm bảo sự cung ứng từ nhà cung cấp đồng thời cũng đảm bảo sự cứng vững, bền và sự an toàn khi xe chạy trên đường.

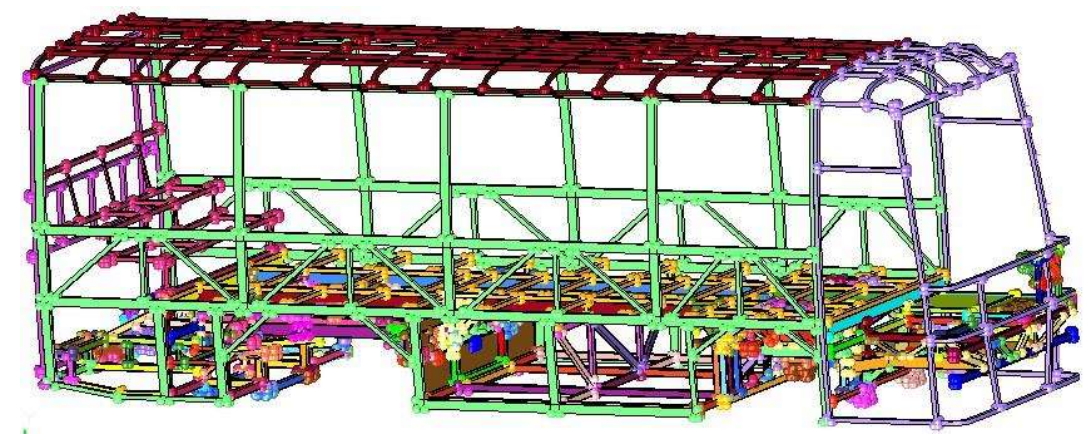

Hình 1: Mô hình 3D tổng thể xe khách 29/34 chỗ ngồi

Khung xương các mảng được chế tạo bằng thép D135 (Nhật Quang), thép D159 (nhập khẩu từ Malaysia), sát-xi được chế tạo bằng thép D357 (nhập khẩu từ Châu Âu), quy cách thép được thể hiện ở bảng 1.

Bảng 1: Bảng quy cách thép khung xương sát-xi

\begin{tabular}{|c|l|c|c|}
\hline STT & \multicolumn{1}{|c|}{ Mảng kết cấu } & Quy cách thép/mm & Tên thép \\
\hline 1 & Mảng đầu & $\square 40 \times 40 \times 1.7$ & D159 \\
\hline 2 & Mảng đuôi & $\square 40 \times 40 \times 1.7$ & D159 \\
\hline 3 & Mảng mui & $\begin{array}{l}\square 20 \times 40 \times 1.4 \\
\square 40 \times 40 \times 1.7\end{array}$ & D159 \\
\hline 4 & Mảng hông trái, phải & $\begin{array}{l}\square 40 \times 40 \times 1.7 \\
\square 40 \times 80 \times 1.9\end{array}$ & D159 \\
\hline 5 & Mảng sàn & $\begin{array}{l}\square 20 \times 40 \times 1.4 \\
\square 40 \times 40 \times 1.7\end{array}$ \\
\hline 6 & Mảng sát-xi & $\begin{array}{l}\square 40 \times 60 \times 4.0 \\
\square 60 \times 60 \times 4.0 \\
\square 60 \times 100 \times 4.0\end{array}$ & D159 \\
\hline
\end{tabular}

\subsection{Mô hình phân tích phần tử hữu hạn}


Dựa vào mô hình CAD ô tô khách, sử dụng phần mềm ALTAIL HYPERWORKS trong môi trường OPTISTRUCT tiến hành xây dựng mô hình phần tử hữu hạn phân tích trạng thái tĩnh ô tô khách. Kết cấu thân xe là khung xương chịu lực, khá phức tạp, do đó cần tiến hành mô hình hoá toàn bộ phần tử các thanh dầm trong quá trình tính toán mô phỏng. Trong quá trình xây dựng mô hình phân tích phần tử hữu hạn, sử dụng loại phần tử thích hợp cho mỗi bài toán là rất quan trọng, nó quyết định đến kết quả tính toán mô phỏng có gần đúng so với mô hình thực tế hay không. Do đó, các kết cấu thanh dầm sử dụng phần tử PSHELL để xây dựng phần tử hữu hạn, kích cỡ lưới $10 \mathrm{~mm}$.

Các bộ phận có khối lượng như hành khách, ghế ngồi, hành lý, thùng nhiên liệu, ắc quy, hệ thống điều hòa không khí, cửa kính,...thì dùng phần tử CONM2 để xây dựng và đặt tại trọng tâm của các bộ phận. Khối lượng các bộ phận được thể hiện ở bảng 2.

Bảng 2: Bảng khối lượng các bộ phận dùng phần tử CONM2 xây dựng

\begin{tabular}{|c|l|c|}
\hline STT & \multicolumn{1}{|c|}{ Tên bộ phận } & Khối lượng/Kg \\
\hline 1 & Khối lượng động cơ, hộp sồ & 530 \\
\hline 2 & Khối lượng thùng nhiên liệu & 150 \\
\hline 3 & Khối lượng kính trước & 100 \\
\hline 4 & Khối lượng kính sau & 50 \\
\hline 5 & Khối lượng kính cửa số (8 cửa) & 240 \\
\hline 6 & Khối lượng accu & 34 \\
\hline 7 & Khối lượng hệ thống điều hòa không khí & 250 \\
\hline 8 & Khối lượng người+ hành lý+ ghế $(29$ người) & 2175 \\
\hline
\end{tabular}

Các cầu xe sử dụng phần tử CBEAM để xây dựng, liên kết giữa cầu xe và sát-xi thông qua phần tử RBE2. Các vị trí nối giữa các thanh, xây dựng mối liên kết cùng tiếp điểm, ngoài ra sử dụng phần tử RBE2 đề hàn các phần tử. Gia tốc trọng trường là $\mathrm{g}=9.8 \mathrm{~m} / \mathrm{s}^{2}$. Kết cấu khung xương và sát-xi sử dụng vật liệu $\mathrm{D} 135$, D159 và $\mathrm{D} 357$, được lấy mẫu thử nghiệm thực tế, thuộc tính vật liệu như ở bảng 3 . Mô hình phần tử hữu hạn ô tô khách 29/34 chỗ được thể hiện ở hình 2.

Bảng 3: Thuộc tính của vật liệu

\begin{tabular}{|c|c|c|c|c|c|}
\hline Tên thép & $\begin{array}{c}\text { Khối lượng } \\
\text { riêng/Kg/m }\end{array}$ & $\begin{array}{c}\text { Mô đun đàn } \\
\text { hồi/GPa }\end{array}$ & Hệ số Poisson & $\begin{array}{c}\text { Úng suất } \\
\text { chảy, } \sigma_{c} / \mathbf{M P a}\end{array}$ & $\begin{array}{c}\text { Úng suất cho } \\
\text { phép } \sigma / \mathbf{M p a} \\
{[12,13]} \\
{[\sigma]=\frac{\sigma_{\mathbf{c}}}{1.5}}\end{array}$ \\
\hline D357 & 7760 & 196 & 0.27 & 470 & 313 \\
\hline D135 & 7840 & 199 & 0.26 & 341 & 227 \\
\hline D159 & 7660 & 196 & 0.28 & 382 & 254 \\
\hline
\end{tabular}

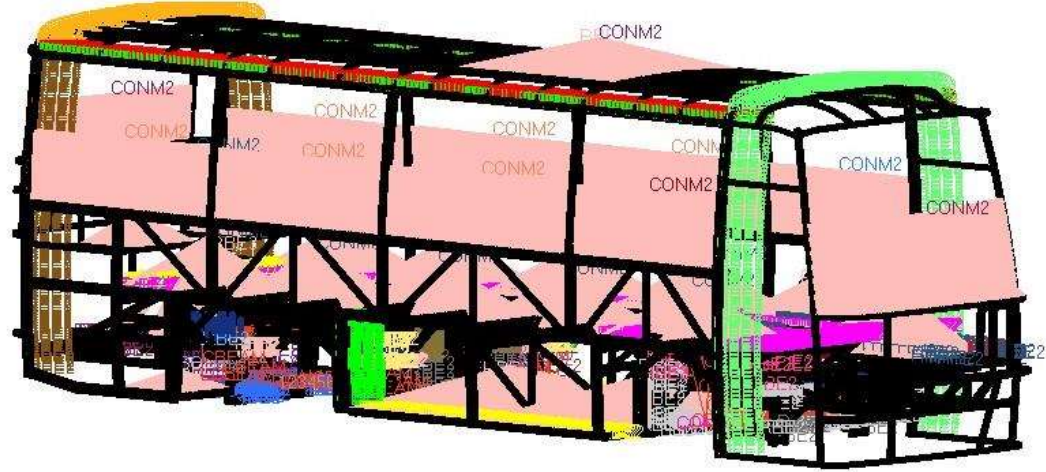

Hình 2: Mô hình phần tử hữu hạn kết cấu thân xe khách

\subsection{Cơ sở tính toán phân tích bền tĩnh}


Để đảm bảo an toàn kết cấu khi xe hoạt động trên đường và đáp ứng được nhu cầu sử dụng của con người thì hệ khung xương sát-xi ô tô khách phải đảm bảo được an toàn. Do đó, tải trọng tĩnh do trọng lượng bản thân khung vỏ, trọng lượng hàng hoá và hành khách cần được nghiên cứu.

Phân tích trạng thái tĩnh kết cấu khung xương và sát-xi ô tô khách nhằm nghiên cứu độ bền kết cấu khi xe hoạt động mọi điều kiện trên đường. Nghiên cứu này khảo sát 4 quá trình làm việc của xe như xe chuyển động thẳng đều (điều kiện uốn), xe chạy trên đường gồ ghề (điều kiện xoắn), xe phanh gấp (điều kiện phanh), xe chạy vào đường cong (điều kiện quay vòng). Nhiều tác giả tiến hành nghiên cứu bền kết cấu xe khách hoạt động ở 4 quá trình uốn, xoắn, phanh, quay vòng [2-6]. Hướng chuyển động của xe trong nghiên cứu này được mô tả ở hình 3 .

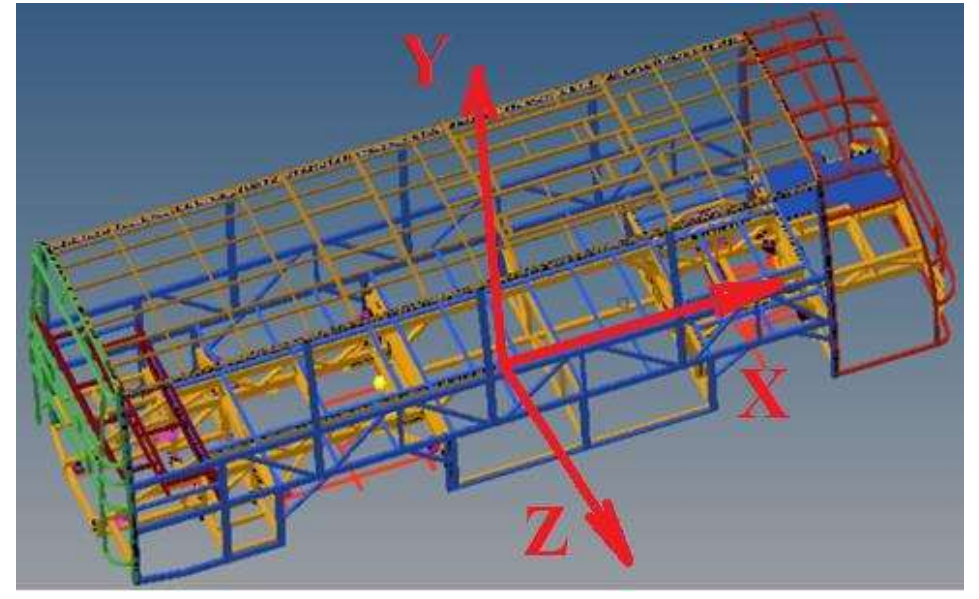

\section{a) Điều kiện uốn}

Hình 3: Hướng chuyển động của xe

Điều kiện uốn là để kiểm tra độ bền của kết cấu khi xe đầy tải chạy trên đường bằng phẳng, ứng suất và biến dạng kết cấu xảy ra dưới tác dụng gia tốc trọng trường [2,5].

Điều kiện biên: Xe khách đặt tại mặt bằng ngang ở trạng thái đầy tải, tại vị trí đặt các bánh xe ở cầu trước, bánh xe ở cầu sau ràng buộc 3 bậc tự do tịnh tiến phương $\mathrm{X}, \mathrm{Y}$ và $\mathrm{Z}$, dồng thời ràng buộc bậc tự do xoay trục $\mathrm{X}$ và $\mathrm{Y}$.

\section{b) Điều kiện xoắn}

Điều kiện xoắn là để kiểm tra độ bền của kết cấu khi xe đầy tải chạy trên đường không bằng phẳng, ứng suất và biến dạng kết cấu xảy ra dưới tác dụng gia tốc trọng trường.

Điều kiện biên: trong điều kiện này xét hai trường hợp sau [5]:

- Trường hợp 1 (TH 1): Ràng buộc ba bậc tự do tịnh tiến và ba bậc tự do xoay ở các trục $\mathrm{X}, \mathrm{Y}$ và $\mathrm{Z}$ tại vị trí đặt bánh trước bên trái, bánh sau bên phải. Các bánh xe còn lại không ràng buộc.

- Trường hợp 2 (TH 2): Ràng buộc ba bậc tự do tịnh tiến và ba bậc tự do xoay ở các trục $\mathrm{X}, \mathrm{Y}$ và $\mathrm{Z}$ tại vị trí đặt bánh xe trước bên phải, bánh xe sau bên trái. Các bánh xe còn lại không ràng buộc.

\section{c) Điều kiện phanh}

Điều kiện này nhằm kiểm tra độ bền kết cấu xe khi xe đầy tải, phanh gấp. Khi đó gia tốc trọng trường theo phương $\mathrm{Y}$ và lực quán tính khi phanh theo phương $\mathrm{X}$ thông qua hệ số bám mặt đường tối đa là 0,8 (giá trị bằng $\varphi$ - hệ số ma sát mặt đường) tác dụng lên kết cấu xe.

Điều kiện biên: Tại vị trí đặt các bánh xe ở cầu trước ràng buộc ba bậc tự do tịnh tiến theo các phương X, $\mathrm{Y}$ và $\mathrm{Z}$; tại vị trí đặt các bánh xe ở cầu sau xe ràng buộc hai bậc tự do tịnh tiến theo các phương $\mathrm{X}$ và $\mathrm{Y}$; đồng thời đặt thêm điều kiện biên gia tốc khi phanh lên toàn bộ xe theo phương $\mathrm{X}$ là $0.8 \mathrm{~g}[2]$.

\section{d) Điều kiện quay vòng}

Trường hợp này khảo sát khi xe đầy tải chạy vào đường cong, do kết cấu hệ khung xương sát-xi không đối xứng, cho nên điều kiện này khảo sát độ bền kết cấu ở hai trường hợp, quay vòng bên trái (TH 1) và quay vòng bên phải (TH 2).

Điều kiện biên: Tại vị trí đặt bánh xe bên phải ở cầu trước ràng buộc ba bậc tự do tịnh tiến theo các phương $\mathrm{X}, \mathrm{Y}$ và $\mathrm{Z}$; tại vị trí đặt bánh xe bên trái ở cầu trước ràng buộc hai bậc tự do tịnh tiến theo các phương $\mathrm{Y}$ và 
Z; tại vị trí đặt hai bánh xe ở cầu sau ràng buộc một bậc tự do tịnh tiến theo phương $\mathrm{Y}$; đồng thời đặt thêm điều kiện biên gia tốc quán tính cho hai trường hợp quay vòng bên trái và quay vòng bên phải lên toàn bộ xe theo phương $\mathrm{Z}$ là $0.4 \mathrm{~g}$ [2].

\section{KẾT QUẢ MÔ PHỎNG PHÂN TÍCH}

Sau khi xây dựng mô hình phần tử hữu hạn và thiết lập điều kiện biên cho bốn quá trình của xe hoạt động trên đường, tiến hành mô phỏng phân tích trên phần mềm OPTISTRUCT. Phần mềm HYPERWIEW được sử dụng xuất kết quả mô phỏng, kết quả ứng suất, chuyển vị của toàn bộ xe được thể hiện ở hình 4 , hình 5 .

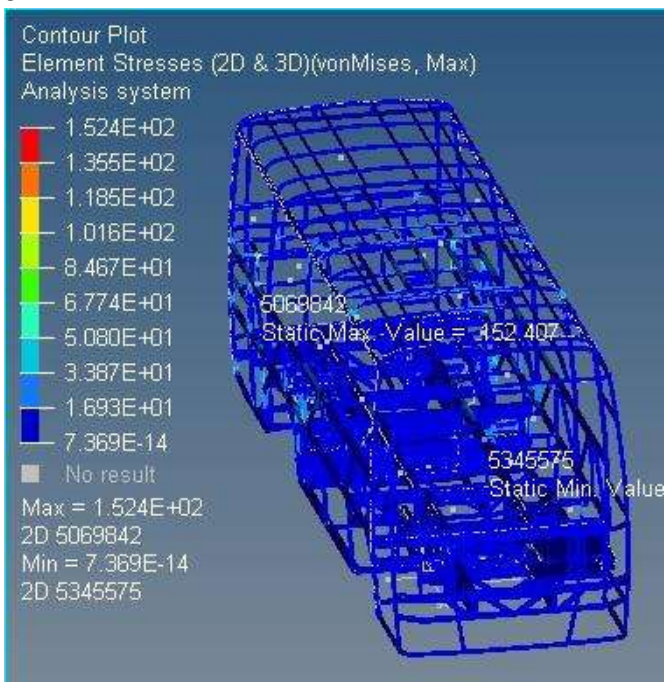

a) Uốn

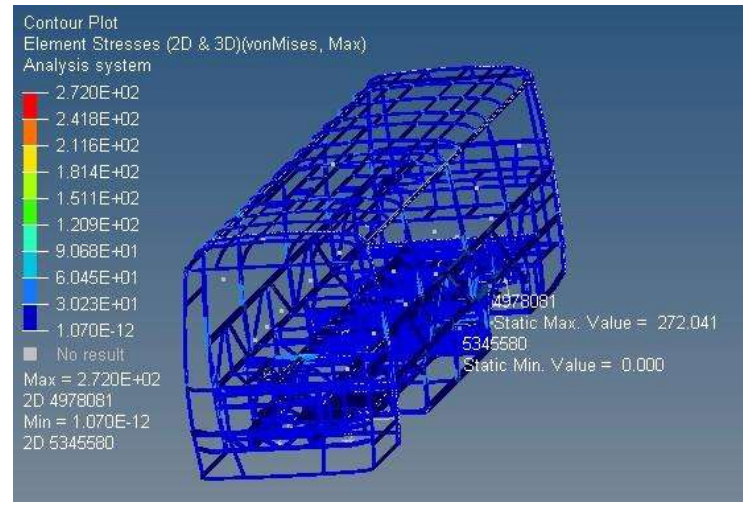

c) Xoắn (TH 2)

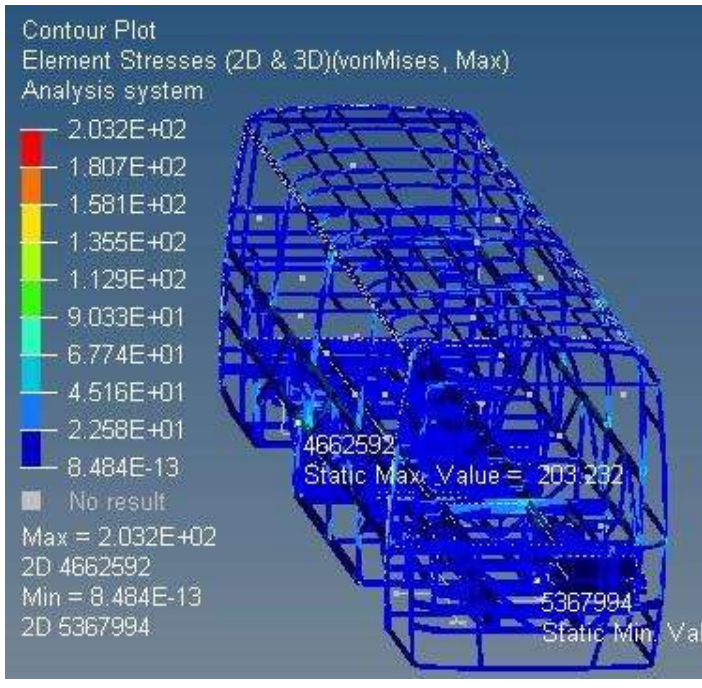

b) Xoắn (TH 1)

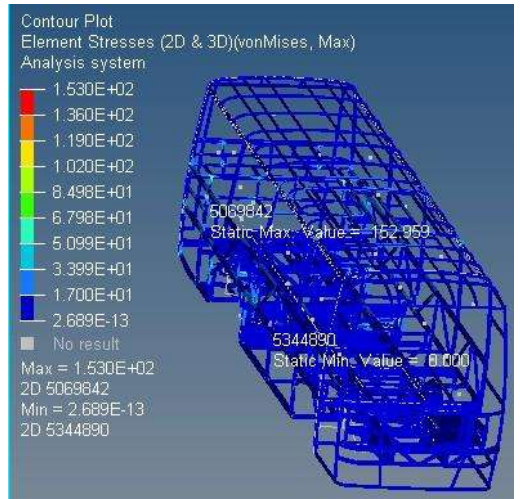

d) Phanh 


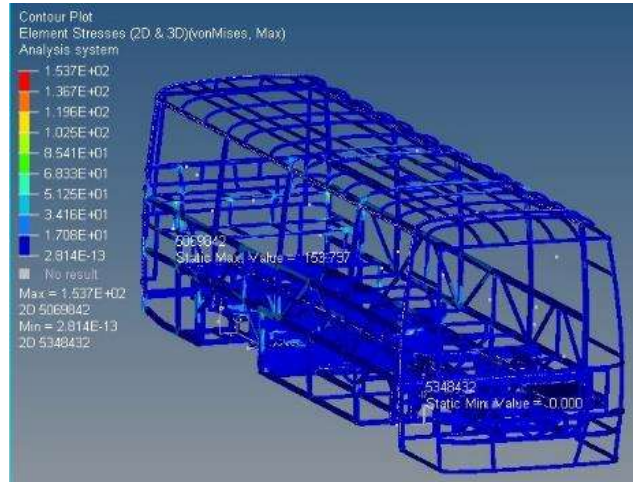

e) Quay vòng ( $\mathrm{TH}$ 1)

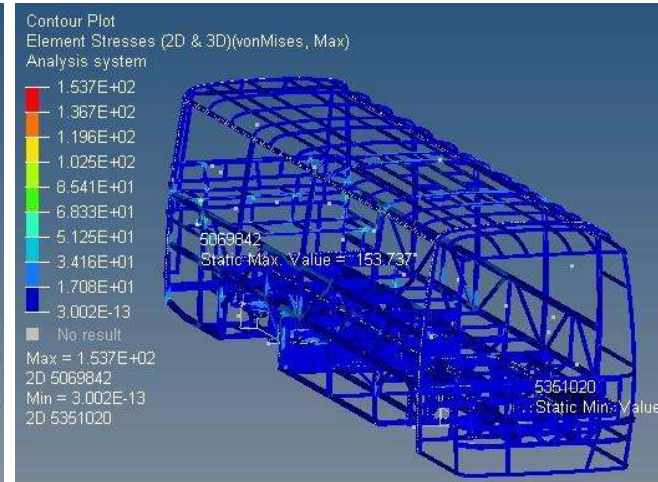

f) Quay vòng ( $\mathrm{TH} 2)$

Hình 4: Kết quả mô phỏng ứng suất cho các quá trình

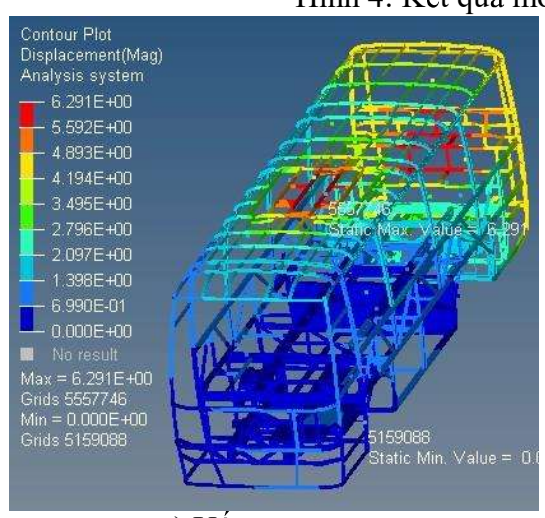

a) Uốn

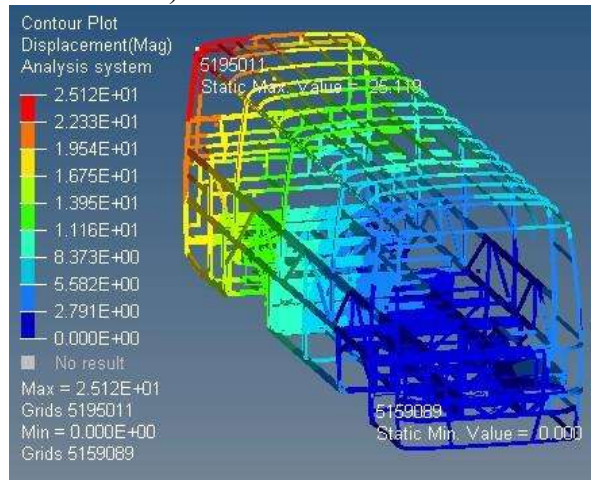

c) Xoắn (TH 2)

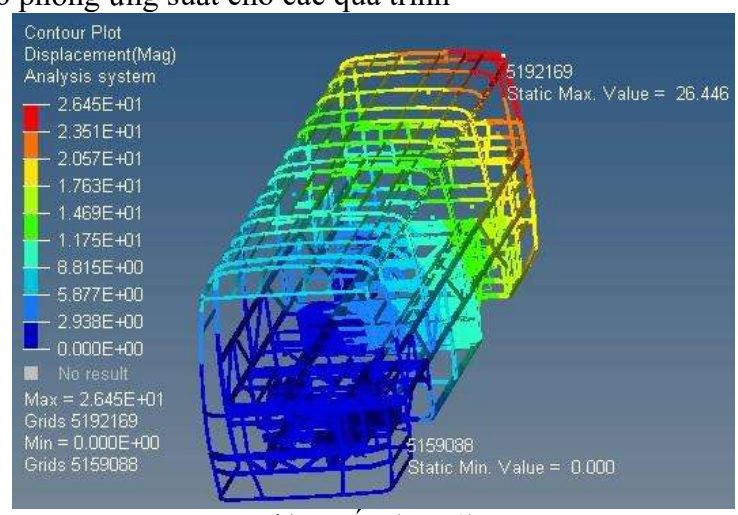

b) Xoắn (TH 1)

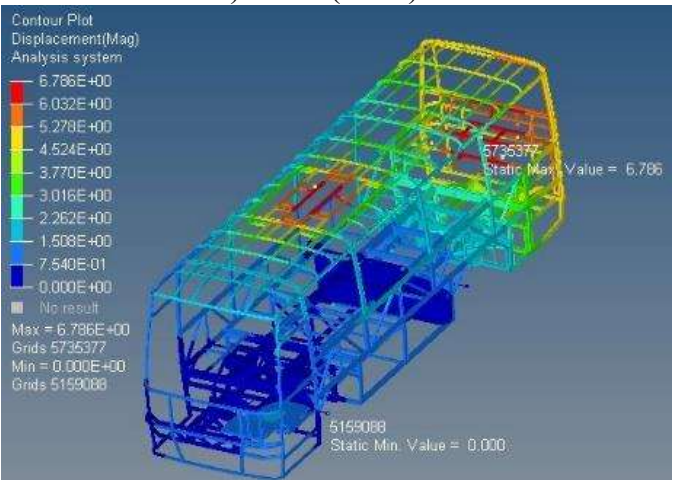

d) Phanh 


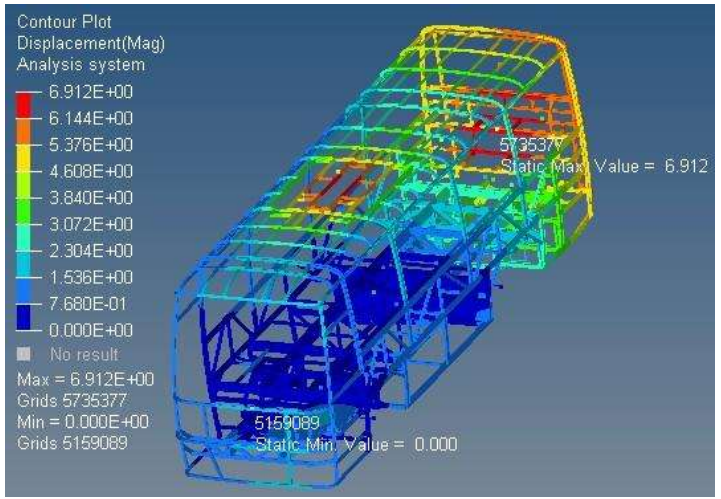

e) Quay vòng ( $\mathrm{TH} 1)$

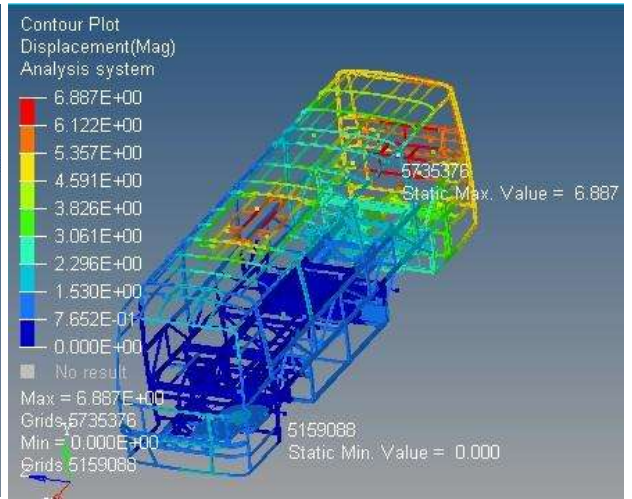

f) Quay vòng ( $\mathrm{TH} 2$ )

Hình 5: Kết quả mô phỏng chuyển vị cho các quá trình

Bảng 4 thể hiện giá trị ứng suất và chuyển vị lớn nhất của kết cấu xe của bốn quá trình hoạt động của xe trên đường.

Bảng 4: Giá trị ứng suất và chuyển vị lớn nhất của các quá trình

\begin{tabular}{|c|c|c|c|c|c|}
\hline STT & Quá trình & $\begin{array}{c}\text { Ứng suất lớn } \\
\text { nhất/MPa }\end{array}$ & $\begin{array}{c}\text { Mảng ứng suất } \\
\text { lớn nhất }\end{array}$ & $\begin{array}{c}\text { Chuyển vị lớn } \\
\text { nhất/mm }\end{array}$ & $\begin{array}{c}\text { Mảng chuyển } \\
\text { vị lớn nhất }\end{array}$ \\
\hline 1 & Uốn & 152.4 & Mảng sàn sau & 6.2 & Mảng sàn sau \\
\hline 2 & Xoắn $(\mathrm{TH} 1)$ & 203.2 & Mảng hông phải & 26.4 & Mảng đuôi \\
\hline 3 & Xoắn $(\mathrm{TH} 2)$ & 272.0 & Mảng sát-xi & 25.1 & Mảng đuôi \\
\hline 4 & Phanh & 153.0 & Mảng sàn sau & 6.7 & Mảng sàn sau \\
\hline 5 & Quay vòng (TH1) & 153.7 & Mảng sàn sau & 6.9 & Mảng sàn sau \\
\hline 6 & Quay vòng (TH2) & 153.7 & Mảng sàn sau & 6.8 & Mảng sàn sau \\
\hline
\end{tabular}

So với các quá trình thì quá trình xoắn $(\mathrm{TH} 2)$ có ứng suất lớn nhất là $272 \mathrm{MPa}$ tại vị trí hàn giữa kết cấu bệ đỡ của hệ thống treo khí với sát-xi, do kết cấu sát-xi sử dụng thép D357 có ứng suất giới hạn là 313 $\mathrm{MPa}$, cho nên ứng suất quá trình xoắn (TH 2 ) nhỏ hơn ứng suất cho phép, thỏa mãn điều kiện bền kết cấu. Ứng suất quá trình xoắn (TH 1) là $203.2 \mathrm{MPa}$ tại mảng hông phải nơi liên kết giữa mảng sàn và mảng hông, do kết cấu hông xe sử dụng thép D135 có ứng suất giới hạn là $227 \mathrm{MPa}$, cho nên ứng suất quá trình xoắn (TH 1) nhỏ hơn ứng suất cho phép, thỏa mãn điều kiện bền kết cấu. Ứng suất các quá trình uốn, phanh, quay vòng có giá trị lần lượt là $152.4 \mathrm{MPa}, 153 \mathrm{MPa}, 153,7 \mathrm{MPa}$ và đều tập trung tại vị trí bên phải của sàn sau, do kểt cấu sàn xe sau sử dụng thép $\mathrm{D} 159$ có ứng suất giới hạn là $254 \mathrm{MPa}$, cho nên ứng suất ở các quá trình này nhỏ hơn ứng suất cho phép, thỏa mãn điều kiện bền kết cấu. Các vị trí có ứng suất lớn nhất được thể hiện ở hình 6 .

Để đánh giá độ cứng của của kết cấu khung xương sát-xi thì phân tích biến dạng kết cấu ở hai khía cạnh, một là biển dạng chuyển vị các khung dầm, hai là tỉ lệ biến dạng của kết cấu khung cửa chính và các kết cấu khung cửa sổ của xe [2]. Từ bảng 4 cho thấy, ở cả hai điều kiện xoắn $(\mathrm{TH} 1)$ và điều kiện xoắn $(\mathrm{TH} 2)$ có giá trị biến dạng chuyển vị lớn nhất, xuất hiện ở hai bên đuôi xe. Nguyên nhân là do trọng tâm của xe nằm phía sau, do đó biến dạng chuyển vị tập trung vào phía sau xe. Hình 7 cho thấy, ở điều kiện xoắn (TH 1) biến dạng chuyển vị lớn nhất ở tại đuôi xe, xét theo hướng $-Y$ thì có giá trị là $20 \mathrm{~mm}$, xét theo hướng $\mathrm{Z}$ thì có giá trị là $19.2 \mathrm{~mm}$. Ở điều kiện xoắn $(\mathrm{TH} 2)$ biến dạng chuyển vị lớn nhất ở tại đuôi xe, xét theo hướng $-\mathrm{Y}$ thì có giá trị là $19.2 \mathrm{~mm}$, xét theo hướng $\mathrm{Z}$ có giá trị là $18 \mathrm{~mm}$, trong khi đó biến dạng chuyển vị theo phương $\mathrm{X}$ có giá trị khá nhỏ. 


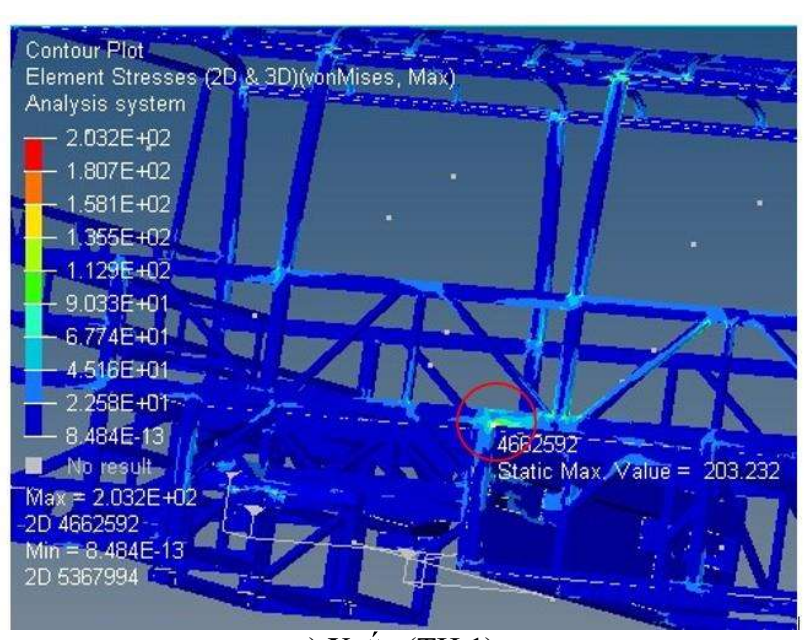

a) Xoắn (TH 1)

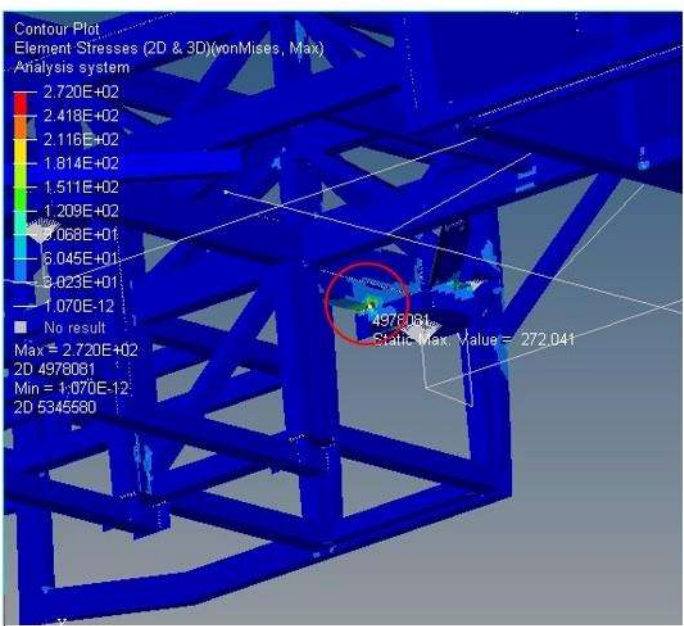

b) Xoắn (TH 2)

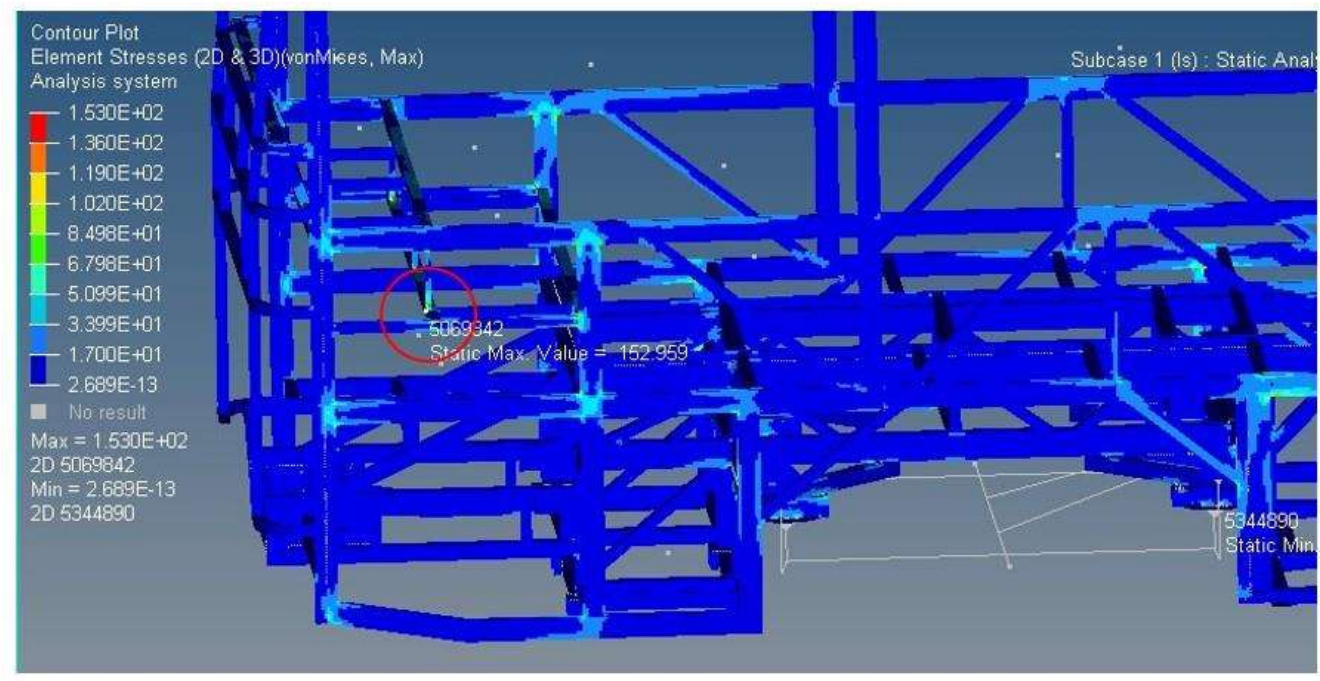

c) Xoắn (TH 2)

Hình 6: Vị trí ứng suất lớn nhất của các quá trình 

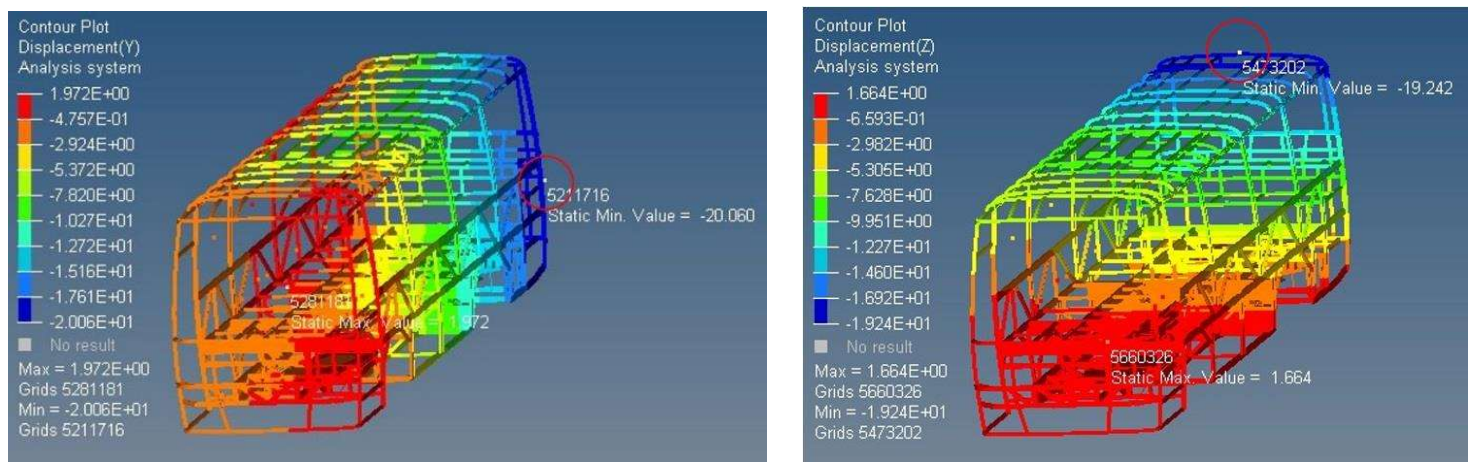

a) Xoắn (TH 1)
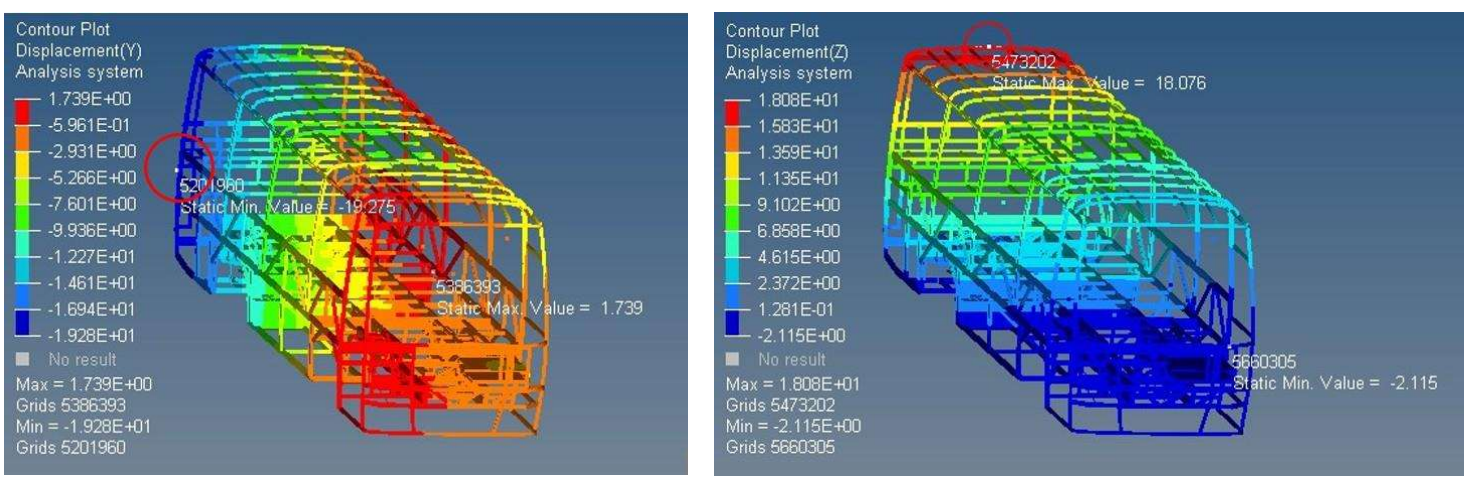

b) Xoắn (TH 2)

Hình 7: Biến dạng chuyển vị lớn nhất quá trình xoắn

Biến dạng kết cấu ảnh hưởng đến độ cứng vững kết cấu, an toàn các bộ phận lắp đặt trên xe, đặc biệt là đảm bảo an toàn của kính trước, kính sau, kính cửa sổ. Tỉ lệ biến dạng các kết cấu khung cửa sổ, kết cấu khung kính trước, kết cấu khung kính sau lớn gây ra mất an toàn, có thể phá hủy kính, gây nguy hiểm đến tính mạng của người. Tiêu chuẩn đánh giá tỉ lệ biến dạng kết cấu phải nhỏ hơn $0.2 \%$ [2]. Các vị trí đánh giá tỉ lệ biến dạng kết cấu bao gồm khung kết cấu kính trước (1), khung kết cấu cửa chính bên trái bên phải (2), khung kết cấu các cửa sổ bên trái bên phải (3),(4),(5),(6) và khung kết cấu kính sau (7), được thể hiện ở hình 8 .

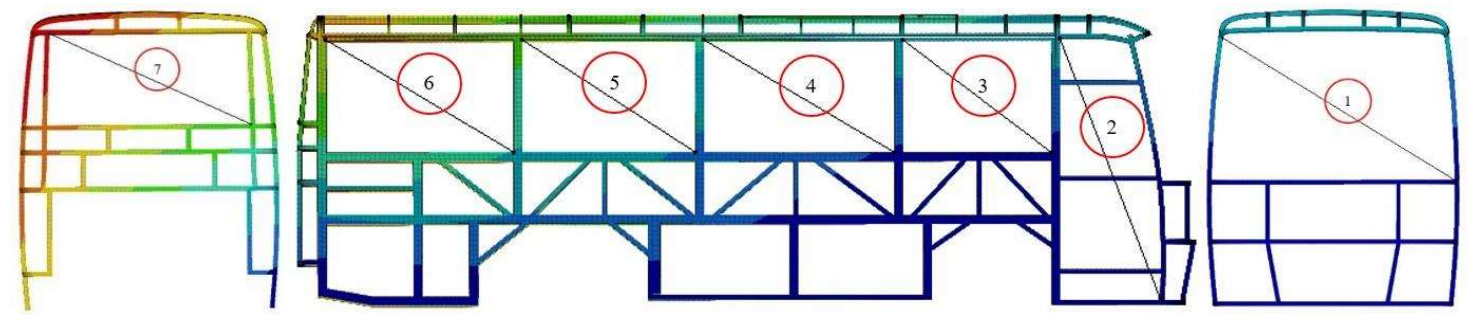

Hình 8: Vị trí đánh giá tỉ lệ biến dạng kết cấu

Bảng 5 thể hiện các giá trị tỉ lệ biến dạng kết cấu khung kính trước, kết cấu khung kính sau, kết cấu khung kính cửa số. Tỉ lệ biến dạng kết cấu khung kính trước ở trường hợp xoắn $(\mathrm{TH} 2)$ có giá trị là $0.1903 \%$, lớn nhất so với các vị trí khác. Tỉ lệ biến dạng kết cấu ở các vị trí khảo sát đều nhỏ hơn $0.2 \%$, do đó kết cấu khung xương sát-xi liền khối chịu lực ồ tô khách 29/34 chỗ ngồi đảm bảo được độ bền khi xe hoạt động trên đường. 
Bảng 5: Tỉ lệ biến dạng kết cấu

\begin{tabular}{|c|c|c|c|c|}
\hline \multirow{2}{*}{ Vị trí } & \multicolumn{2}{|c|}{$\begin{array}{c}\text { Tỉ lệ biến dạng quá trình } \\
\text { xoắn (TH 1)/\% }\end{array}$} & \multicolumn{2}{c|}{$\begin{array}{c}\text { Tỉ lệ biến dạng quá trình } \\
\text { xoắn (TH 2)/\% }\end{array}$} \\
\cline { 2 - 5 } & Trái & Phải & Trái & Phải \\
\hline 1 & -0.1853 & -0.1853 & 0.1903 & 0.1903 \\
\hline 2 & 0.0452 & 0.0000 & 0.0049 & 0.0494 \\
\hline 3 & -0.1145 & 0.1239 & 0.1250 & -0.1317 \\
\hline 4 & -0.1310 & 0.1446 & 0.1474 & -0.1416 \\
\hline 5 & -0.1388 & 0.0683 & 0.0714 & -0.1243 \\
\hline 6 & -0.1128 & 0.0421 & 0.0425 & -0.1000 \\
\hline 7 & -0.0811 & -0.0811 & 0.0915 & 0.0915 \\
\hline
\end{tabular}

\section{KẾT LUÂN}

Nghiên cứu này được thực hiện với sự phối hợp của nhà sản xuất trong nước thiết kế xe khách 29/34 chỗ SAMCO ISUZU có kết cấu khung xương sát-xi liền khối chịu lực monocoque, đây là điểm mới trong nghiên cứu ứng dụng trong nước. Thực hiện tính toán phân tích trạng thái bền tĩnh kết cấu cho bốn quá trình làm việc của xe trên đường như xe chuyển động thẳng đều (điều kiện uốn), xe chạy trên đường gồ ghề (điều kiện xoắn), xe phanh gấp (điều kiện phanh), xe chạy vào đường cong (điều kiện quay vòng). Kết quả phân tích cho thấy, giá trị ứng suất, biến dạng kết cấu xe ở các quá trình xe hoạt động trên đường đều thỏa mãn điều kiện an toàn cho phép, trong đó ở quá trình xoắn có giá trị lớn nhất. Kết quả nghiên cứu cho thấy, kết cấu khung xương sát-xi liền khối chịu lực của xe 29/34 chỗ ngồi được thiết kế đảm bảo được độ bền khi xe hoạt động trên đường.

\section{TÀI LIỆU THAM KHẢO}

[1] Khairul Jauhari and Mahfudz Alhuda, Strength Analysis of Frame Structures of Medium Monocoque Bus using Finite Element Method and Test Results. National Conference Proceeding of Mechanical Engineering XI (SNTTM XI) \& Thermofluid IV Gadjah Mada University (UGM), Yogyakarta, 16-17 October 2012.

[2] Qiang Zhu and Xiaomei Li, Light Weight Research of Monocoque City Bus Body Frame. 2016 6th International Conference on Information Technology for Manufacturing Systems (ITMS 2016).

[3] Tian Fang, Wang Tao and Shi Qin, Finite Element Analysis for Monocoque Bus/Coach Body Structure. Bus \& Coach Technology and Research. No 1: 17-19, 2012.

[4] Hailiang Wang, Xianlong Jin and Zhongqin Lin, FEM Static and Dynamic Analysis of the Body Structure of SK6120 Low Floor City Bus. SAE Technical. 2002-01-0813.

[5] Dario Croccolo, Massimiliano De Agostinis and Nicolò Vincenzi, Structural Analysis of an Articulated Urban Bus Chassis via FEM: a Methodology Applied to a Case Study. Journal of Mechanical Engineering. 57 (2011) 11, 799-809.

[6] Zhuo Yang, Baoqing Deng, Mengqi Deng and Gongrui Sun, A Study on Finite Element Analysis of Electric Bus Frame for Lightweight Design. MATEC Web of Conferences 175, 03049, (2018). IFCAE-IOT 2018.

[7] Satish Kumar, Arun Kumar Gupta and Pankaj Chandna, Static, Dynamic and Impact Stress Analysis of A Bus Body Structure Using Finite Element Analysis. International Journal of Mechanical and Production Engineering Research and Development (IJMPERD). Vol. 8, Issue 1, Feb 2018, 733-744.

[8] Liu Jiang, Gui Liangjin, Wang Qingchun and Fan Zijie, Multi-objective Optimization on the Body Structure of Integral Bus. Automotive Engineering. 30 (2), 170-173, 2008. 
[9] Trần Hữu Nhân, Phan Đình Huấn, Phạm Xuân Mai. Nghiên cứu tính toán tối ưu hoá kết cấu thân xe buýt. Chuyên đề nghiên cứu, Trường Đại học Bách khoa Thành phố Hồ Chí Minh. 2005.

[10] Nguyễn Thành Tâm. Thiết kế tối ưu hóa kết cấu khung xương và sát - xi ô tô khách. Khoa học Giáo dục Kỹ thuạt, 31(2015): 29-35.

[11] Nguyễn Quang Anh, Nghiên cứu động lực học và độ bền của khung vỏ ô tô khi va chạm trực diện, Học Viện Kỹ Thuật Quân Sự, Hà Nội, 2007.

[12] Jason C. Brown, A. John Robertson and Stan T. Serpento, Motor Vehicle Structures-Concepts and Fundamentals. Butterworth-Heinemann. Oxford OX2 8DP. 2002.

[13] Maciej Szulc, Ireneusz Malujda, Krzysztof Talaśka. Method of determination of safety factor on example of selected structure. Procedia Engineering, 136 (2016 ) 50 - 55.

Ngày nhận bài: 29/05/2020

Ngày chấp nhận đăng:23/10/2020 